\title{
Erratum to: Measuring Student Career Interest within the Context of Technology-Enhanced STEM Projects: a Cross-Project Comparison Study Based on the Career Interest Questionnaire
}

\author{
Karen Peterman $^{1} \cdot$ Ruth Kermish-Allen $^{2}$ - Gerald Knezek ${ }^{3} \cdot$ Rhonda Christensen $^{4}$ • \\ Tandra Tyler-Wood ${ }^{3}$
}

Published online: 8 November 2016

(C) Springer Science+Business Media New York 2016

Erratum to: J Sci Educ Technol

DOI 10.1007/s10956-016-9617-5

The original version of this article inadvertently did not include the Acknowledgments:

Acknowledgments We would like to thank Erik daSilva, Nancy Miles, Jane Robertson, and Michael Weatherwax for assisting in data collection and coding for the E4ME evaluation. This work was supported by the National Science Foundation under grant numbers \# 1029696, \#0833706, and \#1312168. Any opinions, findings, and conclusions or recommendations expressed in this material are those of the author(s) and do not necessarily reflect the views of the National Science Foundation.

The online version of the original article can be found at http://dx. doi.org/10.1007/s10956-016-9617-5

Karen Peterman

karenpetermanphd@gmail.com

Karen Peterman Consulting, Co., 2706 Stuart Drive,

Durham, NC 27707, USA

2 Maine Math and Science Alliance, 219 Capitol Street Suite 3, Augusta, ME 04330, USA

3 Department of Learning Technologies, University of North Texas, 3940 N. Elm, Denton, TX 76207, USA

4 Institute for the Integration of Technology into Teaching and Learning, University of North Texas, Denton, TX 76207, USA 